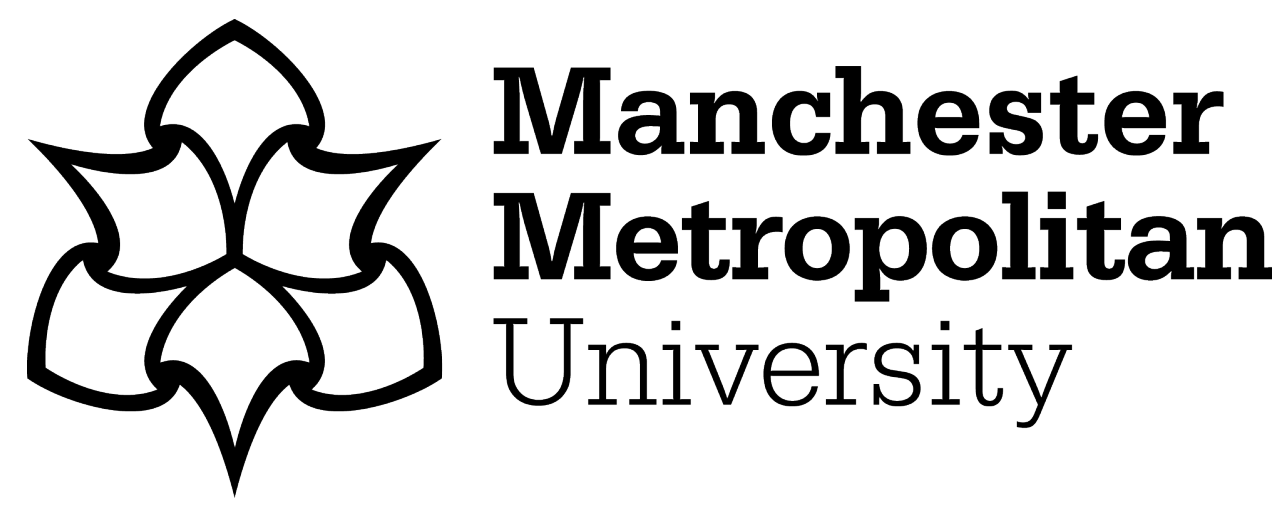

Maricar, Nasimah ORCID logoORCID: https://orcid.org/0000-0001-95035991, Parkes, Matthew J, Callaghan, Michael J ORCID logoORCID: https://orcid.org/0000-0003-3540-2838, Felson, David T and O'Neill, Terence W (2019) Do Clinical Correlates of Knee Osteoarthritis Predict Outcome to Intra-Articular Steroid Injections? The Journal of Rheumatology, 46 (4). pp. 331-441. ISSN 0315-162X

Downloaded from: https://e-space.mmu.ac.uk/623626/

Version: Accepted Version

Publisher: The Journal of Rheumatology Publishing Co. Ltd.

DOI: https://doi.org/10.3899/jrheum.180233

Please cite the published version 


\section{R| $\mid \begin{aligned} & \text { The Journal of } \\ & \text { Rheumatology }\end{aligned}$}

\section{The Journal of Rheumatology}

Do Clinical Correlates of Knee Osteoarthritis Predict Outcome to Intra-Articular Steroid Injections?

Nasimah Maricar, Matthew J. Parkes, Michael J. Callaghan, David T. Felson and Terence W. O'Neill

DOI: 10.3899/jrheum.180233

http://www.jrheum.org/content/early/2019/03/24/jrheum.180233

1. Sign up for TOCs and other alerts

http://www.jrheum.org/alerts

2. Information on Subscriptions

http://jrheum.com/faq

3. Information on permissions/orders of reprints

http://jrheum.com/reprints_permissions

The Journal of Rheumatology is a monthly international serial edited by Earl D.

Silverman featuring research articles on clinical subjects from scientists working in rheumatology and related fields.

Downloaded from www.jrheum.org on April 15, 2019 - Published by The Journal of Rheumatology 


\title{
Do Clinical Correlates of Knee Osteoarthritis Predict Outcome to Intra-Articular Steroid Injections?
}

\author{
Nasimah Maricar ${ }^{1,2,3}$, Matthew J Parkes ${ }^{1,2}$, Michael J Callaghan ${ }^{1,2,4}$, David T Felson ${ }^{1,2,5}$, Terence W
}

O’Neill ${ }^{1,2,6}$

${ }^{1}$ Arthritis Research UK Centre for Epidemiology, Division of Musculoskeletal \& Dermatological Sciences, Faculty of

Biology, Medicine and Health, Manchester Academic Health Science Centre, The University of Manchester,

Manchester, UK

${ }^{2}$ NIHR Manchester Biomedical Research Centre, Manchester University NHS Foundation Trust, Manchester Academic

Health Sciences Centre, Manchester, UK.

${ }^{3}$ Department of Physiotherapy, Salford Royal NHS Foundation Trust, Manchester, UK.

${ }^{4}$ Department of Health Professions, Manchester Metropolitan University, Manchester, UK.

${ }^{5}$ Clinical Epidemiology Unit, Boston University School of Medicine, Boston, MA, USA.

${ }^{6}$ Department of Rheumatology, Salford Royal NHS Foundation Trust, Manchester, UK.

\section{Address correspondence:}

Nasimah Maricar, NIHR Clinical Doctoral Fellow, Research in Osteoarthritis Manchester (ROAM), Arthritis Research UK Centre for Epidemiology, Division of Musculoskeletal \& Dermatological Sciences, Faculty of Biology, Medicine and Health, Manchester Academic Health Science Centre, The University of Manchester, Manchester, UNITED KINGDOM, M13 9PT (nasimah.maricar@manchester.ac.uk; nasimah.maricar@srft.nhs.uk)

\author{
Declarations of interest \\ None \\ Email addresses: \\ Nasimah Maricar (nasimah.maricar@manchester.ac.uk) \\ Matthew J Parkes (matthew.parkes@manchester.ac.uk) \\ Michael J Callaghan (michael.callaghan@mmu.ac.uk) \\ David T Felson (david.felson@manchester.ac.uk) \\ Terence O'Neill (terence.o'neill@manchester.ac.uk)
}

\section{Ethical approval and consent to participate}

Subjects were provided with an information sheet about the study and those who agreed to take part subsequently provided written informed consent. Ethics approval was received from the Leicestershire Multicentre Research Ethics Committee (reference:09/H0402/107).

\section{Funding}

This study was funded by Arthritis Research UK grant 20380, and special strategic award grant 18676. The funding agency had no role in any of the following: design and conduct of the study; collection, management, analysis, and interpretation of the data; and preparation, review, or approval of the manuscript; and decision to submit the manuscript for publication.

This report includes independent research supported by (or funded by) the National Institute for Health Research

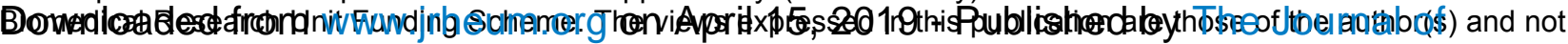
Rheumatology 
necessarily those of the NHS, the National Institute for Health Research or the Department of Health. The Research in Osteoarthritis Manchester (ROAM) group is supported by the Manchester Academic Health Sciences Centre (MAHSC). Prof. Felson is supported by NIH AR4778. Nasimah Maricar is supported by an NIHR Allied Health Profession Clinical Doctoral Fellowship.

\section{Acknowledgements}

We appreciate the expert assistance of Helen Williams, Laura Heathers, Laura Forsythe, Rosie Perry, and the rest of the ROAM team. The authors are thankful for the generous contributions of time and energy of study participants. The authors would like to acknowledge the equipment and facilities provided by the Salford Royal NHS Foundation Trust 


\section{Abstract}

Background.To determine if clinical correlates of knee osteoarthritis(OA) affect likelihood of outcome to intra-articular steroid injections(IASI) in symptomatic knee OA.

Method.Men and women aged $\geq 40$ years with painful knee OA who participated in an open label trial of IASI completed questionnaires and clinical examination. OMERACT-OARSI criteria were used to assess response to therapy in the short-term(within 2-weeks). Among those who initially responded, those whose pain had not returned to within $20 \%$ of the baseline KOOS-pain score at 6-months were characterised as longer-term responders. Log binomial regression was used to examine factors associated with outcome.

Results.199 participants were included, of whom 146(73.4\%) were short-term and 40(20.1\%) longer-term responders. Compared to short-term non-responders, participants with medial joint-line tenderness $(R R=1.42 ; 1.10-1.82)$, medial \& lateral joint-line tenderness $(R R=1.38 ; 1.03-1.84)$, patellofemoral tenderness $(R R=1.27 ; 1.04-1.55)$, anserine tenderness $(R R=1.27 ; 1.06-1.52)$ and a belief that treatment would be effective(RR/unit increase, [range $0-10]=1.05 ; 1.01-1.09)$, were more likely to be short-term responders. Aspiration of joint fluid(RR=0.79;0.66-0.95) and previous ligament/meniscus injury $(R R=0.63 ; 0.44-0.91)$ were associated with a reduced risk of being a short-term responder. Compared to initial non-responders and those whose pain recurred within 6-months, participants with higher number of pain sites(RR/unit increase, [range 0-10] $=0.83 ; 0.72-0.97)$, chronic widespread pain $(R R=0.32 ; 0.10-0.98)$, perceived chronicity of disease $(\mathrm{RR} /$ unit increase, [range $0-10]=0.86 ; 0.78-0.94)$ and a higher depression score $(R R /$ unit increase, [range 0-21] $=0.89 ; 0.81-0.99)$ were less likely to be longer-term responders.

Conclusion. Among patients with symptomatic knee OA, tenderness around the knee was associated with better short-term outcome to IASI. However, clinical-related factors did not predict longer-term response while those with chronic widespread pain and depressive symptoms were less likely to obtain longer-term benefit.

Keywords: predictors, knee osteoarthritis, intra-articular steroid injection, clinical tests, psychological

Downloaded from www.jrheum.org on April 15, 2019 - Published by The Journal of Rheumatology 


\section{Introduction}

Intra-articular steroid injection(IASI) is an effective treatment for many individuals with symptomatic osteoarthritis $(\mathrm{OA})$ of the knee with short-term pain-relief lasting up to 4 weeks ${ }^{1-5}$ and longer-term response up to 24 weeks ${ }^{1,6}$. Previous systematic reviews and meta-analyses have shown there is variation in both the magnitude and duration of symptom-relief following steroid injections ${ }^{1,3,7}$. Evidence from recent systematic reviews suggests, however, no factor consistently linked with response ${ }^{7,8}$. In more recent analyses, using an individual patient data meta-analysis of randomized controlled trials, patients with severe baseline pain were found to benefit more from a steroid injection than those with less severe pain ${ }^{9}$. The presence of inflammatory signs did not appear to influence outcome ${ }^{9-11}$. While in a study of 174 women increasing age, reduced knee range of movement(ROM), increased local knee tenderness and more severe radiographic disease were associated with a reduced response to IASI at 3-months ${ }^{12}$. In a recent prospective study in individuals with knee OA, no clinical, radiographic, sonographic and serological characteristics influenced response other than female gender which was associated with response at three weeks $(p=0.045)$, and previous injection with non-response at nine weeks $(p=0.021)^{11}$. In a different prospective cohort study where repeated IASI were undertaken in predominantly knee OA of KellgrenLawrence $(K L)$ 1-3, patients with persisting pain or ultrasound effusion at 1-month after IASI showed a reduced probability to respond to additional injections and to treatment response at 1 -year ${ }^{13}$.

There are few data concerning the impact of psychological factors on treatment response ${ }^{7}$. In our recent open-label study of IASI in knee OA ${ }^{14,15}$, not all participants responded to the therapy in the short-term. Of those who responded, the majority had a recurrence of pain within 6-months. In previous work, we looked at the impact of disease severity on outcome following IASI and found that those with more severe disease[either magnetic resonance imaging(MRI) or $\mathrm{x}$-ray] were less likely to be longer-term responders ${ }^{14,15}$. The aim of the current study was to determine the impact of a range of clinical correlates of disease including symptoms, clinical signs of knee OA, psychologic factors and quality of life, on both short-term(within 2-weeks) and longer-term(6-months) outcome following IASI. Our IASI predictor of outcome study was larger in scale and longer in follow-up than prior studies, and was also designed to look at a more comprehensive list of predictor factors to IASI treatment. 


\section{Methods}

Participants

Men and women aged 40 years and over were recruited from primary and secondary care for participation in an open-label study looking at efficacy of IASI in symptomatic knee OA(ISRCTN: 07329370). Participants were included if they reported moderate knee pain for more than 48 hours in the previous 2weeks or scored greater than 7 out of 32 on the Knee Injury and Osteoarthritis Outcome Score(KOOS) questionnaire, questions P2-P9(question P1 relates to frequency of knee pain, which is irrelevant given the inclusion criteria on pain frequency). Inclusion criteria included imaging confirmation of definite knee OA either radiologically $[K L \geq 2$ on postero-anterior, lateral or skyline view in any knee compartment in the past 2 years] or, if no x-rays were obtained, evidence of OA on MRI or at arthroscopy. For MRI and arthroscopy, typical changes of OA with at least cartilage loss present were required. Exclusion criteria included gout, septic arthritis, inflammatory arthritis, hyaluronic acid or steroid injection within the previous 3-months, knee surgery within the previous 6-months and concurrent life threatening illnesses ${ }^{14,15}$. Participants were provided with study information sheets and subsequently gave written informed consent if they agreed to participate. Ethics approval was received from the Leicestershire Multicentre Research Ethics Committee(reference 09/H0402/107).

\section{Screening and baseline assessment}

Participants were assessed for eligibility at a screening visit ${ }^{14}$. Those who fulfilled the inclusion/exclusion criteria were invited to attend a baseline visit. Participants also completed questionnaires including the KOOS-pain scale(relating to the index knee) where higher score denotes lower severity of symptoms ${ }^{16}$, a global perception of change-Likert scale, a Visual Analogue Scale(VAS) score for pain during an activity that a patient nominated as being most troublesome(VAS $\mathrm{NA}_{\mathrm{NA}}$, Short-Form-12(SF-12) ${ }^{17}$, Hospital Anxiety Depression scale(HADS) ${ }^{18}$ and IIIness Perception Questionnaires-Brief(IPQ-B $)^{19}$. The SF-12 is a validated survey designed to assess health status with both mental and physical health-related quality of life ${ }^{20,21}$. HADS is a 14-item scale, scored $0-3$ with seven items each, measuring anxiety and depression over the last week ${ }^{18}$. The IPQ-B provides a quantitative assessment of five components of cognitive and emotional representations of illness using Leventhal's Self-Regulatory Model and includes 8 items scored $0-10$ with a

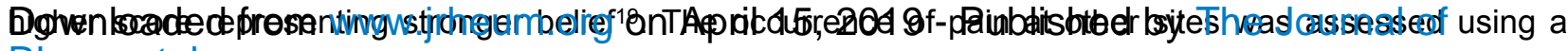
Rheumatology 
manikin for body pain(4 figures:front, back, left and right side); participants were asked to complete this for aches and pain which lasted longer than one day that they experienced in the past month ${ }^{22}$. A further question asked about whether they had been aware of the pain for more than 3-months. Chronic Widespread Pain(CWP) was defined as pain experienced in contralateral quadrants of the body, above and below the waist and in the axial skeleton that had persisted for more than 3-months ${ }^{23,24}$. We also noted the number of the shaded regions on the manikin to reflect the number of pain sites ${ }^{23,24}$.

A subsample $(n=103)$ of participants had additional clinical tests performed by one of two assessors prior to having their steroid injections using standardised assessment procedures. These additional tests included assessment of bony enlargement(absent $=0$, unsure $=1$, present $=2$ ), joint crepitus(absent $=0$, unsure $=1$, present palpable $=2$, present audible $=3$ ), quadriceps muscle wasting(absent $=0$, possible $=1$, present $=2$ ), assessment of effusion using the bulge $\operatorname{sign}^{25}$, assessment of effusion using the ballottement test(absent=0, present without click=1, present with click $(\operatorname{tap})=2)$, patellofemoral joint tenderness(absent $=0$, present $=1$ ), pes anserine tenderness $(a b s e n t=0$, present $=1$, medial tibiofemoral joint tenderness $(a b s e n t=0$, present $=1)$, lateral tibiofemoral joint tenderness $(a b s e n t=0$, present $=1$ ) and goniometric knee ROM, flexion and extension measured to the nearest degrees ${ }^{26}$. Maximal voluntary isometric strength of the quadriceps was measured by a strain gauge using a protocol developed for past studies ${ }^{27}$. Strength scores were measured as torque in Newton meters $(\mathrm{Nm})$ and normalized for body size using the formula corrected strength=Nm/(weight in $\mathrm{kg} \times$ [height in $\mathrm{m}$ divided by 2]). The length of the distal lower limb was taken to allow calculation of torque. For the elements of the clinical examination, reliability evaluation intra- $(K=0.60-0.98 ; \mathrm{ICC}=0.96-0.99)$ and inter-observer $(\mathrm{K}=0.48-1.00 ; \mathrm{ICC}=0.87-0.97)$ showed moderate to excellent agreement ${ }^{28}$. While kappa can be affected by the prevalence, in our study for most clinical signs the prevalence was not particularly low. We also asked participants 'Have you ever been told you have injured your ligaments or meniscus in your affected knee(yes, no, don't know)'.

Following the assessments, arthrocentesis was performed with removal of synovial fluid(if present) and injection of $80 \mathrm{mg}$ methylprednisolone acetate(without local anaesthetic). The majority of injections were undertaken non-guided using a medial approach to the knee joint by one of two experienced clinicians(TON/NM). Following further ethics approval, during the course of the study, we used ultrasound to guide localisation of the injections for the remaining subjects using lateral approach to the suprapatellar pursa(NM). Any participant in whom the synovjal fluid white cell çunt(WCC) was found to be greater than Downloaded from www.jrheum.org on April 15, 2019 - Published by The Journal of Rheumatology 
$1,500 / \mathrm{mm}^{3}$ was excluded due to concerns they might have a primary inflammatory arthritis. We treated and studied one knee per participant.

\section{Follow-up}

We defined response to IASI using the OMERACT-OARSI responder criteria based on the KOOS-pain scale and global perception of change-Likert scale ${ }^{29}$. A responder was defined as having either (i)greater or equal to $20 \%$ change in KOOS-pain score and a "slightly" or "much better" score on the 5-point Likert scale for change in pain, or (ii)greater or equal to $50 \%$ change in the KOOS-pain score; in both cases an absolute change of at least 3 units if the baseline KOOS-pain score was 15 or less. Participants were seen usually within 2-weeks after the injection and we characterised their response at that time as short-term response. Those who had not responded were not further followed. Those who responded were followed with regular telephone calls every 4-weeks during which the same KOOS-pain questions and global-Likert scale were administered. Those whose pain recurred to within $20 \%$ of the baseline KOOS-pain score were defined as having relapsed and were seen again for final follow-up. Those whose pain levels did not return to this level at 6-months of follow-up were classified as 'longer-term responders'.

\section{Analysis}

Means and standard deviations(SD) for normally-distributed variables, and medians and interquartile ranges(IQR) for variables with a skewed distribution, were used to summarise participant characteristics. Log-binomial regression was used to determine whether baseline factors were associated with both shortterm response(i.e. those who responded within 2-weeks vs those who did not) and longer-term response(those who were responders at 6-months vs those who did not respond initially or, who were initial responders and whose pain subsequently recurred within 6-months) to therapy. In all the analyses the outcome was responder status(yes vs no). All categorical predictors were coded as dummy variables, thereby making no assumptions about the relationship between categories, in terms of order(rank) or scale. This process was repeated for all categorical predictors, including those with ordinal categories(for example, bulge sign). Due to low frequencies in subcategories, the crepitus and ballottement variables were collapsed into dichotomous variables, coded as (absent $=0$, present palpable and/or audible $=1$ ), and (absent=0, present with/without click=1), respectively. Any factors which were significantly associated with outcome were then included in a subsequent multivariable analysis(two models; one for short-term [using Downloaded from www.jrheum.org on April 15, 2019 - Published by The Journal of Rheumatology 
Poisson regression with robust standard errors] and one for longer-term responders[using log-binomial regression]) to examine whether associations were retained in the presence of other predictors. Results were expressed as Relative Risks(RR) and 95\% confidence intervals(Cl). No adjustment was undertaken for multiple comparisons ${ }^{30}$. Statistical analysis was undertaken using Stata version 14(StataCorp, College Station, Texas).

\section{Results}

Participants

209 participants were recruited. Two were withdrawn following recruitment because they received a steroid injection from their General Practitioner(Figure 1). Following intervention with IASI, a further 8 were withdrawn for a number of reasons as listed in Figure 1. Out of the remaining 199 participants, 103 had additional assessments performed. The mean age of the 199 remaining in the study was 62.8 years $(S D=10.3)$ and $105(52.8 \%)$ were female(Table 1a). Median KOOS pain score at baseline was 44.4 points $(I Q R=36.1-55.6)$, and median $V_{A S}$ was $7.0 \mathrm{~cm}(I Q R=5.6-8.1)($ Table 1a). The median time between baseline and first follow-up visit was 8 days(IQR=7-14). Median KOOS pain and $\mathrm{VAS}_{\mathrm{NA}}$ at baseline, first follow-up and at 6-months stratified by responder status is presented in Table 1a. Other participant characteristics including the psychological factors, quality of life and clinical related factors are presented in Tables $1 \mathrm{a}$ and $1 \mathrm{~b}$. The baseline characteristics of subjects who received their injections unguided were broadly similar to those who received their injections guided(Table 2). There was no difference in the demographic characteristics or pain symptoms in those subjects who had additional clinical assessments performed and those who did not(online supplementary table 1). Our findings with respect to a subsample $(n=120)$ of participants who had an MRI of their knee performed have been published $^{14,15}$.

\section{Predictors of Short-Term Responder Status}

Of those participants who had an IASI, 146(73.4\%) were defined as short-term responders. Those with medial tibiofemoral joint tenderness $(R R=1.42 ; 95 \% \mathrm{Cl} 1.10-1.82)$, medial \& lateral tibiofemoral joint tenderness $(R R=1.38 ; 95 \% \mathrm{Cl} 1.03-1.84)$, patellofemoral tenderness $(R R=1.27 ; 95 \% \mathrm{Cl} 1.04-1.55)$, or anserine tenderness $(\mathrm{RR}=1.27 ; 95 \% \mathrm{Cl} 1.06-1.52)$, and also those with a positive belief about treatment with IASI(IPQ-B Treatment Score)(RR per unit increase $=1.05 ; 95 \% \mathrm{Cl} 1.01-1.09)$ were more likely to be Downloaded from www.jrheum.org on April 15, 2019 - Published by The Journal of Rheumatology 
responders, while aspiration of synovial fluid $(R R=0.79 ; 95 \% \mathrm{Cl} 0.66-0.95)$ and previous ligament or meniscus injury(RR=0.63;95\% $\mathrm{Cl} 0.44-0.91)$ were associated with a reduced likelihood of being a shortterm responder(Table 3 and 4). None of the other patient-related factors including the use of guided injection, psychological factors, quality of life or clinical signs of disease was linked with short-term responder status(Table 3 and 4). In a multivariable analysis of the factors that were associated with shortterm response only one factor(previous ligament or meniscus injury) remained significant after adjustment (online supplementary table 2).

\section{Predictors of Longer-Term Responder Status (6-months)}

40 participants from those who were short-term responders $(20.1 \%$ of the original cohort of 199 participants) were characterised as longer-term responders where at 6-months, their pain had not returned to within $20 \%$ of their baseline value. The presence of $\mathrm{CWP}(\mathrm{RR}=0.32 ; 95 \% \mathrm{Cl} 0.10-0.98)$ was associated with a reduced likelihood of being a longer-term responder(Table 3). An increased number of pain sites(RR=0.83/site;95\% Cl 0.72-0.97), perceived chronicity of disease(IPQ-B Timeline Score;RR per unit increase $=0.86 ; 95 \% \mathrm{Cl} 0.78-0.94)$ and depressive symptoms(RR per unit increase $=0.89 ; 95 \% \mathrm{Cl} 0.81-0.99$ ) were also associated with a reduced likelihood of being a longer-term responder(Table 3). Categorisation of these variables suggest a linear relationship for both depressive symptoms and timeline score(online supplementary Table 3). None of the clinical signs of OA, the use of guided injection or aspiration, or other factors linked with short-term response were associated with longer-term response status(Table 3 and 4). In a multivariable analysis of the factors associated with longer-term response, only the IPQ-B timeline score remained significant after adjustment(online supplementary table 4).

\section{Discussion}

In this open-label study of IASI, using OMERACT-OARSI criteria as our definition of response, we found several factors associated with short-term response status. Knee tenderness and a stronger belief about the effectiveness of treatment were linked with a response to IASI while aspiration of synovial joint fluid and having prior ligament or meniscus injury were linked with a reduced risk of response. None of these factors though were linked with longer-term response status. In contrast, depressive symptoms and the presence of CWP were associated with a reduced risk of being a longer-term responder.

Downloaded from www.jrheum.org on April 15, 2019 - Published by The Journal of Rheumatology 
Compared to those who did not respond to IASI, those who were short-term responders were more likely to have medial tibiofemoral joint tenderness, medial \& lateral joint-line tenderness, patellofemoral joint tenderness and anserine tenderness. Our findings are in keeping with one study, where clinical assessment of local tenderness was linked with an improved response at 3-weeks(OR=1.80;95\% $\mathrm{Cl} 1.03-$ $1.67)^{31}$.

Previous studies do not support the impression that the presence of knee effusion is associated with response; with only two $0^{32,33}$ of six studies ${ }^{5,31-35}$ suggesting that response was better in those with effusion. In our study the presence of a clinical effusion(as determined by the bulge sign or ballottement) was not associated with treatment response, while aspiration of synovial fluid, if anything was linked with a reduced response to IASI. We did not though have information about clinical signs of effusion at follow-up. No other symptoms or clinical signs of OA were associated with response. We found in our previous analysis on structural predictors to IASI that MRI-effusion and MRI-synovitis were not linked with an improved response ${ }^{14,15}$. Interestingly though among a subsample of subjects in whom synovial fluid(SF) analysis was performed, compared to those with a SF WCC in the lowest tertile $\left(<100 \mathrm{cells} / \mathrm{mm}^{3}\right)$ those with WCC in the middle and upper tertile had a greater reduction in knee pain following steroid injection ${ }^{36}$.

Compared to short-term non-responders, a higher proportion of short-term responders received their injection using ultrasound-guided control(41.8\% vs $34 \%)$. This difference, although not statistically significant may, however, be clinically relevant and further large scale studies are needed to confirm whether or not ultrasound guidance is linked with an improved outcome. Sibbitt $\mathrm{Jr}$ et al. ${ }^{37}$ reported that guided knee injections(compared with blinded injections) were associated with one-month longer of painrelief, though guided injections did not lead to better improvement of pain response in the longer-term(6months). We did not have objective assessment of localisation of the needle to within the joint and so were unable to determine whether accurate localisation within the joint was linked with response. The results of a recent study, using air-arthrosonogram as an indicator of accuracy of localisation, however, suggest that accurate localisation of IASI to the knee did not result in superior outcome in terms of pain compared to inaccurate injection ${ }^{11}$.

There are few studies which have looked at the influence of adverse psychological factors on treatment response. Our null findings for anxiety and depression are in keeping with the study of Jones and Doherty 31 Downloaded from www.jrheum.org on April 15, 2019 - Published by The Journal of Rheumatology 
suggesting no impact on response in the short-term. It is perhaps not surprising, that those who had a stronger belief that treatment was going to be effective had a beneficial effect. As we did not have detailed information about previous steroid injections to explore whether it was prior experience of a successful outcome which may have driven their illness beliefs in relation to treatment response, we cannot exclude this possibility. We note though the findings of a recent study in which participants who had had a previous experience of injection were less likely to report response to treatment than those undergoing their first injection at 9-weeks but not 3-weeks ${ }^{11}$.

In contrast to our findings on 'disease' related factors predicting short-term response, we found no evidence that these were linked with longer-term response. We had anticipated that those with more marked clinical features of disease such as crepitus and bony enlargement and muscle wasting may also have been less likely to be responders; however, this did not appear to be the case.

A number of factors including CWP, having multiple sites of bodily pain, perceived chronicity of disease and depressive symptoms were linked with a reduced likelihood of being a longer-term responder. The observation is in keeping with studies suggesting chronic pain, negative attitude and depression can be predictors of poorer treatment outcome in other clinical settings ${ }^{38-41}$. It is possible that altered pain sensitivity or awareness of pain as a consequence of the psychological symptoms, may have influenced the likelihood of poorer longer-term response.

There were several limitations to the study. Although this was a comparatively large study, the high frequency of the(short-term) response and relatively low frequency of some predictors mean that this study was relatively under-powered to detect some predictors of outcome. Further larger studies are needed to determine the impact of the putative predictor variables on outcome. Characterisation of the clinical predictors was based on clinical examination, which is subject to measurement errors. The effect of errors of classification of individual clinical signs due to poor reliability would tend to reduce the chance of finding real biological associations-however, formal testing of reliability in the study was good suggesting that this is unlikely to have been important in explaining our findings ${ }^{28}$. Other putative predictor variables were obtained largely by self-report and therefore subject to errors of recall; these factors though were obtained prior to intervention and it seems unlikely that any such errors would have resulted in bias, though may have perhaps led to reduced precision in estimates of effect. There was no placebo group in the trial as the Downloaded from www.jrheum.org on April 15, 2019 - Published by The Journal of Rheumatology 
short-term efficacy of IASI in knee OA is already established ${ }^{1-3,5}$. Whilst it is likely that some of the response may be due to a contextual/placebo effect, the trial reflects clinical practice in which injections are administered in an 'open' setting with the patient aware of the intervention and so the observed 'predictor' variables are likely to reflect those which would be observed in the clinical setting. Another limitation was the possible effect of 'multiplicity' as in this study we looked at a range of putative determinants without correcting for testing and therefore a risk that some of the predictors found could be circumstantial and for which replication of the findings may be needed. The variables, however, which we considered were those which we felt could plausibly impact on the outcome. Further it is possible that some real biological associations may have been missed(type 2 errors). As outlined earlier, we could not exclude the possibility that previous IASI and/or their response may have influenced some of the results. The study was performed in predominantly Caucasian population and the results should be generalised beyond this setting with caution.

What are the clinical implications of our findings? Our data suggest there may be a limited role for clinical phenotyping in relation to targeting IASI therapy in patients with joint disease though due to the exploratory nature of our study, other studies are required to confirm our findings. While knee tenderness was linked with an improved response at short-term, the effect was relatively small and unlikely to be of clinical utility; short-term response for those with patellofemoral or medial tibiofemoral joint-line tenderness was $86 \%$ and $87.5 \%$ compared with $70 \%$ and $67 \%$ for those without, respectively. The data also suggest that targeting therapy based on symptoms including, for example, the presence or absence of a knee effusion should not influence the decision about whether or not to undertake the steroid injection. As outlined, psychologic factors, including depressive symptoms and presence of widespread pain, and greater number of pain sites, although not impacting on short-term outcome, reduced the likelihood of longer-term response; this reinforces the importance of targeting these other symptoms in any overall management strategy to reduce knee pain due to OA. Based on our data such factors should not influence the decision to treat patients with more widespread pain if the target is short-term improvement.

\section{Conclusion}

Among patients with symptomatic knee osteoarthritis, those with knee tenderness are more likely to respond to IASI therapy. Clinical signs of knee OA did not, however, predict longer-term response. The 
presence of CWP, having multiple sites pain and depressive symptoms attenuates longer-term treatment response.

\author{
Reference List
}

(1) Arroll B, Goodyear-Smith F. Corticosteroid injections for osteoarthritis of the knee: meta-analysis. BMJ 2004;328:869-873.

(2) Bellamy N, Campbell J, Welch V, Gee TL, Bourne R, Wells GA. Intraarticular corticosteroid for treatment of osteoarthritis of the knee. Cochrane Database of Systematic Reviews : Reviews 2009 Issue 2 John Wiley \& Sons , 2009.

(3) Bjordal JM, Klovning A, Ljunggren AE, Slordal L. Short-term efficacy of pharmacotherapeutic interventions in osteoarthritic knee pain: A meta-analysis of randomised placebo-controlled trials. Eur J Pain 2007;11:125-138.

(4) Juni P, Hari R, Rutjes AW, Fischer R, Silletta MG, Reichenbach S et al. Intra-articular corticosteroid for knee osteoarthritis. Cochrane Database Syst Rev 2015;CD005328.

(5) Chao J, Wu C, Sun B, Hose MK, Quan A, Hughes TH et al. Inflammatory characteristics on ultrasound predict poorer longterm response to intraarticular corticosteroid injections in knee osteoarthritis. J Rheumatol 2010;37:650-655.

(6) Smith MD, Wetherall M, Darby T, Esterman A, Slavotinek J, Roberts-Thomson P et al. A randomized placebo-controlled trial of arthroscopic lavage versus lavage plus intra-articular corticosteroids in the management of symptomatic osteoarthritis of the knee. Rheumatology (Oxford) 2003;42:1477-1485.

(7) Maricar N, Callaghan MJ, Felson DT, O'Neill TW. Predictors of response to intra-articular steroid injections in knee osteoarthritis--a systematic review. Rheumatology (Oxford) 2013;52:1022-1032.

(8) Hirsch G, Kitas G, Klocke R. Intra-articular corticosteroid injection in osteoarthritis of the knee and hip: Factors predicting pain relief-A systematic review. Semin Arthritis Rheum 2013;42:451-473.

(9) van Middelkoop M, Arden NK, Atchia I, Birrell F, Chao J, Rezende MU et al. The OA Trial Bank: meta-analysis of individual patient data from knee and hip osteoarthritis trials show that patients with severe pain exhibit greater benefit from intra-articular glucocorticoids. Osteoarthritis Cartilage 2016;24:1143-1152.

(10) Bevers K, Zweers MC, Vriezekolk JE, Bijlsma JW, den Broeder AA. Are ultrasonographic signs of inflammation predictors for response to intra-articular glucocorticoids in knee osteoarthritis? Clin Exp Rheumatol 2014;32:930-934.

(11) Hirsch G, O'Neill TW, Kitas G, Sinha A, Klocke R. Accuracy of injection and short-term pain relief following intra-articular corticosteroid injection in knee osteoarthritis - an observational study. BMC Musculoskelet Disord 2017;18:44.

(12) Fatimah N, Salim B, Raja EU, Nasim A. Predictors of response to intra-articular steroid injections in patients with osteoarthritis of the knee joint. Clin Rheumatol 2016;35:2541-2547.

(13) Calvet J, Orellana C, Galisteo C, Garcia-Manrique M, Navarro N, Caixas A et al. Clinical and ultrasonographic features associated to response to intraarticular corticosteroid injection. A one year follow up prospective cohort study in knee osteoarthritis patient with joint effusion. PLoS One

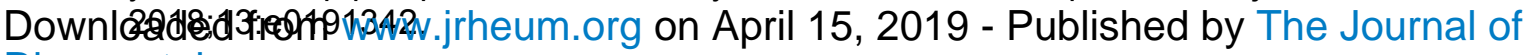
Rheumatology 
(14) O'Neill TW, Parkes MJ, Maricar N, Marjanovic EJ, Hodgson R, Gait AD et al. Synovial tissue volume: a treatment target in knee osteoarthritis (OA). Ann Rheum Dis 2016;75:84-90.

(15) Maricar N, Parkes MJ, Callaghan MJ, Hutchinson CE, Gait AD, Hodgson R et al. Structural predictors of response to intra-articular steroid injection in symptomatic knee osteoarthritis. Arthritis Res Ther 2017; 19:88.

(16) Roos EM, Roos HP, Lohmander LS, Ekdahl C, Beynnon BD. Knee Injury and Osteoarthritis Outcome Score (KOOS)--development of a self-administered outcome measure. J Orthop Sports Phys Ther 1998;28:88-96.

(17) Hurst NP, McRorie ER. The short-term health outcome of out-patient rheumatology consultations in relation to rationing: a pilot study. $\mathrm{Br} \mathrm{J}$ Rheumatol 1998;37:509-513.

(18) Zigmond AS, Snaith RP. The hospital anxiety and depression scale. Acta Psychiatr Scand 1983;67:361-370.

(19) Broadbent E, Petrie KJ, Main J, Weinman J. The brief illness perception questionnaire. J Psychosom Res 2006;60:631-637.

(20) Carmona L, Ballina J, Gabriel R, Laffon A. The burden of musculoskeletal diseases in the general population of Spain: results from a national survey. Ann Rheum Dis 2001;60:1040-1045.

(21) Hagen KB, Smedstad LM, Uhlig T, Kvien TK. The responsiveness of health status measures in patients with rheumatoid arthritis: comparison of disease-specific and generic instruments. J Rheumatol 1999;26:1474-1480.

(22) Harkness EF, Macfarlane GJ, Silman AJ, McBeth J. Is musculoskeletal pain more common now than 40 years ago?: Two population-based cross-sectional studies. Rheumatology (Oxford) 2005;44:890-895.

(23) Nicholl BI, Macfarlane GJ, Davies KA, Morriss R, Dickens C, McBeth J. Premorbid psychosocial factors are associated with poor health-related quality of life in subjects with new onset of chronic widespread pain - results from the EPIFUND study. Pain 2009;141:119-126.

(24) Woolf AD, Pfleger B. Burden of major musculoskeletal conditions. Bull World Health Organ 2003;81:646-656.

(25) Sturgill LP, Snyder-Mackler L, Manal TJ, Axe MJ. Interrater reliability of a clinical scale to assess knee joint effusion. J Orthop Sports Phys Ther 2009;39:845-849.

(26) Clarkson HM. Musculoskeletal Assessment: Joint Range of Motion and Manual Muscle Strength. 2nd ed. Baltimore: Williams \& Wilkins, 1999.

(27) Lord SR, Allen GM, Williams P, Gandevia SC. Risk of falling: predictors based on reduced strength in persons previously affected by polio. Arch Phys Med Rehabil 2002;83:757-763.

(28) Maricar N, Callaghan MJ, Parkes MJ, Felson DT, O'Neill TW. Interobserver and Intraobserver Reliability of Clinical Assessments in Knee Osteoarthritis. J Rheumatol 2016;43:2171-2178.

(29) Pham T, van der HD, Altman RD, Anderson JJ, Bellamy N, Hochberg M et al. OMERACT-OARSI initiative: Osteoarthritis Research Society International set of responder criteria for osteoarthritis clinical trials revisited. Osteoarthritis Cartilage 2004;12:389-399.

(30) Rothman KJ. No adjustments are needed for multiple comparisons. Epidemiology 1990;1:43-46.

(31) Jones A, Doherty M. Intra-articular corticosteroids are effective in osteoarthritis but there are no

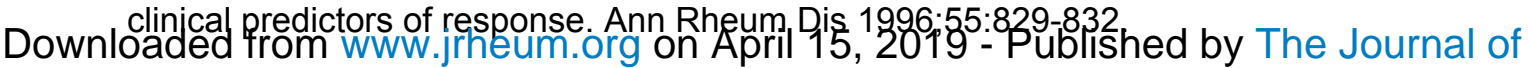
Rheumatology 
(32) Arden NK, Reading IC, Jordan KM, Thomas L, Platten H, Hassan A et al. A randomised controlled trial of tidal irrigation vs corticosteroid injection in knee osteoarthritis: the KIVIS Study. Osteoarthritis Cartilage 2008;16:733-739.

(33) Gaffney K, Ledingham J, Perry JD. Intra-articular triamcinolone hexacetonide in knee osteoarthritis: factors influencing the clinical response. Ann Rheum Dis 1995;54:379-381.

(34) Pendleton A, Millar A, O'Kane D, Wright GD, Taggart AJ. Can sonography be used to predict the response to intra-articular corticosteroid injection in primary osteoarthritis of the knee? Scand $\mathrm{J}$ Rheumatol 2008;37:395-397.

(35) Pyne D, loannou Y, Mootoo R, Bhanji A. Intra-articular steroids in knee osteoarthritis: a comparative study of triamcinolone hexacetonide and methylprednisolone acetate. Clin Rheumatol 2004;23:116-120.

(36) McCabe PS, Parkes MJ, Maricar N, Hutchinson CE, Freemont A, O'Neill TW et al. Brief Report: Synovial Fluid White Blood Cell Count in Knee Osteoarthritis: Association With Structural Findings and Treatment Response. Arthritis Rheumatol 2017;69:103-107.

(37) Sibbitt WL, Jr., Band PA, Kettwich LG, Chavez-Chiang NR, Delea SL, Bankhurst AD. A randomized controlled trial evaluating the cost-effectiveness of sonographic guidance for intraarticular injection of the osteoarthritic knee. J Clin Rheumatol 2011;17:409-415.

(38) de Rooij A, van der Leeden M, Roorda LD, Steultjens MP, Dekker J. Predictors of outcome of multidisciplinary treatment in chronic widespread pain: an observational study. BMC Musculoskelet Disord 2013;14:133.

(39) Karjalainen K, Malmivaara A, Mutanen P, Pohjolainen T, Roine R, Hurri H. Outcome determinants of subacute low back pain. Spine 2003;28:2634-2640.

(40) McCracken LM, Turk DC. Behavioral and cognitive-behavioral treatment for chronic pain: outcome, predictors of outcome, and treatment process. Spine 2002;27:2564-2573.

(41) Reimer M, Hullemann P, Hukauf M, Keller T, Binder A, Gierthmuhlen J et al. Prediction of response to tapentadol in chronic low back pain. Eur J Pain 2016;21:322-333.

Downloaded from www.jrheum.org on April 15, 2019 - Published by The Journal of Rheumatology 
Figure 1 PRISMA Flow chart of participants

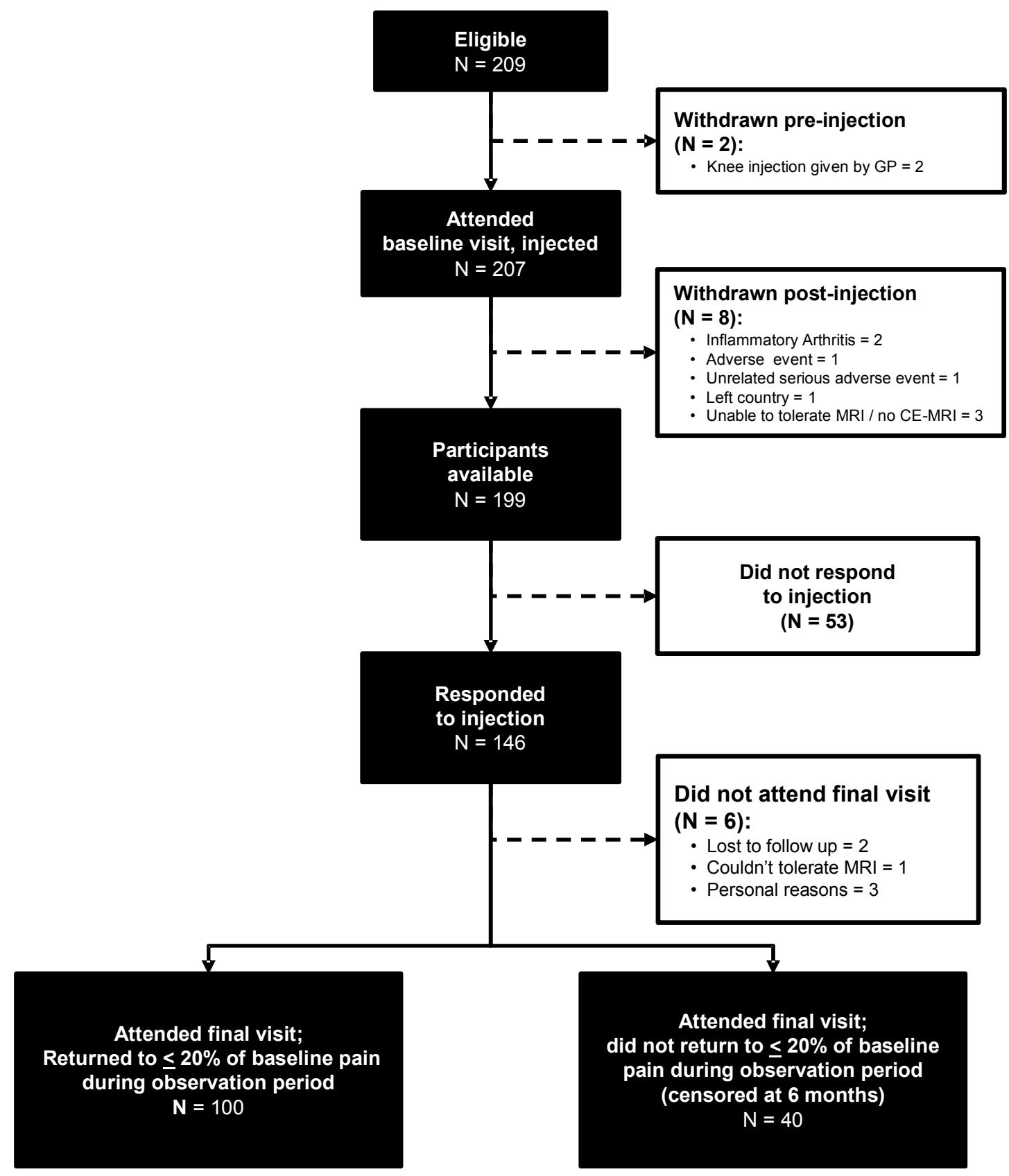

Downloaded from www.jrheum.org on April 15, 2019 - Published by The Journal of Rheumatology 


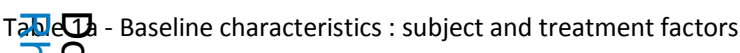

\begin{tabular}{|c|c|c|c|c|c|c|c|c|c|c|c|}
\hline \multirow{3}{*}{ 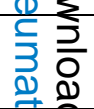 } & \multirow{3}{*}{ Variable } & \multirow{2}{*}{\multicolumn{2}{|c|}{ Full Sample }} & \multicolumn{4}{|c|}{ First Follow Up Visit } & \multicolumn{4}{|c|}{6 months Visit } \\
\hline & & & & \multicolumn{2}{|c|}{ Non-Responder } & \multicolumn{2}{|r|}{ Responder } & \multicolumn{2}{|c|}{ Non-Responder } & \multicolumn{2}{|r|}{ Responder } \\
\hline & & Na & Statistic & $\mathrm{Na}$ & Statistic & Na & Statistic & $\mathrm{Na}$ & Statistic & $\mathrm{Na}$ & Statistic \\
\hline$\frac{\operatorname{sem}}{0} \mathrm{~g}^{r a}$ & ic / Prior Knee Injury & & & & & 116 & & & & & \\
\hline$\vec{\pi}$ & Females, frequency (\%) & 199 & $105(52.8)$ & 52 & $22(41.5)$ & 146 & $83(56.9)$ & 159 & $83(52.2)$ & 40 & $22(55.0)$ \\
\hline & & & & & & & & & & 40 & \\
\hline & OOS-pain subscale score $(0-100)^{*}$, median (IQR) & 199 & $44.4(36.1$ to 55.6$)$ & 53 & $44.4(38.9$ to 61.1$)$ & 146 & 44.4 (36.1 to 52.8$)$ & 159 & $44.4(36.1$ to 55.6$)$ & 40 & $\begin{array}{l}44.4(36.1 \text { to } 52.8) \\
\quad 72(6.4 \text { to } 81)\end{array}$ \\
\hline & Pain in last w eek VAS $(0-10 \mathrm{~cm})^{* *}$, median (IQR) & 194 & $6.5(5.0 \text { to } 8.0)^{\mathrm{n}}$ & 50 & $6.8(3.3$ to 8.0$)$ & 144 & $6.5(5.0$ to 8.0$)$ & 154 & $6.5(4.8$ to 8.0$)$ & 40 & $6.5(5.1$ to 8.1$)$ \\
\hline & Number of Pain Sites, median (IQR) & 177 & $4.0(2.0$ to 5.0$)$ & 47 & $4.0(2.0$ to 6.0$)$ & 130 & $3.0(2.0$ to 5.0$)$ & 143 & $4.0(2.0$ to 5.0$)$ & 34 & $2.0(2.0$ to 4.0$)$ \\
\hline 2) & Chronic Widespread Pain (ACR), frequency (\%) & 150 & $39(26.0)$ & 38 & $11(29.0)$ & 112 & $28(25.0)$ & 120 & $36(30.0)$ & 30 & $3(10.0)$ \\
\hline 3lo & cal factors & & & & & & & & & & \\
\hline 3 & HAD - Anxiety, median (IQR) & 170 & $6.5(3.0$ to 9.0$)$ & 45 & $6.0(3.0$ to 9.0$)$ & 125 & 7.0 (3.0 to 9.0$)$ & 137 & $7.0(3.0$ to 9.0$)$ & 33 & $5.0(2.0$ to 9.0$)$ \\
\hline 0 & HAD-Depression, median (IQR) & 170 & $4.0(2.0$ to 8.0$)$ & 45 & $5.0(3.0$ to 8.0$)$ & 125 & $4.0(2.0$ to 7.0$)$ & 137 & $5.0(2.0$ to 8.0$)$ & 33 & $3.0(2.0$ to 6.0$)$ \\
\hline 10 & IPQ-B Consequences Score, median (IQR) & 175 & $6.0(4.0$ to 8.0$)$ & 46 & $7.0(4.0$ to 8.0$)$ & 129 & $6.0(4.0$ to 8.0$)$ & 141 & 7.0 (4.0 to 8.0$)$ & 34 & $6.0(4.0$ to 7.0$)$ \\
\hline ه & IPQ-B Timeline Score, median (IQR) & 172 & $10.0(8.0$ to 10.0$)$ & 46 & $10.0(7.0$ to 10.0$)$ & 126 & $9.0(8.0$ to 10.0$)$ & 139 & $10.0(8.0$ to 10.0$)$ & 33 & 8.0 (6.0 to 10.0$)$ \\
\hline & IPQ-B Personal Control Score, median (IQR) & 173 & $5.0(2.0$ to 7.0$)$ & 45 & $5.0(2.0$ to 6.0$)$ & 128 & $4.0(2.0$ to 7.0$)$ & 140 & $5.0(2.0$ to 7.0$)$ & 33 & $4.0(3.0$ to 7.0$)$ \\
\hline I & IPQ-B Treatment Score, median (IQR) & 174 & $8.0(5.0$ to 10.0$)$ & 46 & $7.0(5.0$ to 8.0$)$ & 128 & $8.0(6.0$ to 10.0$)$ & 141 & $8.0(5.0$ to 10.0$)$ & 33 & $8.0(7.0$ to 9.0$)$ \\
\hline & IPQ-B Identity Score, median (IQR) & 175 & $7.0(6.0$ to 9.0$)$ & 46 & $7.5(5.0$ to 8.0$)$ & 129 & $7.0(6.0$ to 9.0$)$ & 142 & $7.0(6.0$ to 9.0$)$ & 33 & $7.0(6.0$ to 8.0$)$ \\
\hline & |PQ-B IIIness Concern Score, median (IQR) & 174 & $7.0(5.0$ to 9.0$)$ & 46 & $7.5(5.0$ to 9.0$)$ & 128 & 7.0 (5.0 to 9.0$)$ & 141 & $7.0(5.0$ to 9.0$)$ & 33 & $7.0(5.0$ to 8.0$)$ \\
\hline & IPQ-B Coherent Score, median (IQR) & 172 & $8.0(7.0$ to 10.0$)$ & 46 & $8.0(6.0$ to 10.0$)$ & 126 & $8.0(7.0$ to 10.0$)$ & 139 & $8.0(7.0$ to 10.0$)$ & 33 & $8.0(7.0$ to 10.0$)$ \\
\hline & -B Emotional Representation Score, median (IQR) & 172 & $5.0(2.0$ to 7.0$)$ & 46 & $5.0(2.0$ to 8.0$)$ & 126 & $5.0(2.0$ to 7.0$)$ & 139 & $5.0(2.0$ to 7.0$)$ & 33 & $5.0(1.0$ to 7.0$)$ \\
\hline Quarige & & & & & & & & & & & \\
\hline & SF-12 Physical Component Summary, mean (SD) & 184 & $32.3(8.7)$ & 50 & $31.7(8.8)$ & 134 & $32.5(8.7)$ & 147 & $32.2(8.9)$ & 37 & $32.6(8.0)$ \\
\hline & SF-12 Mental Component Summary, mean (SD) & 184 & $49.2(11.7)$ & 50 & $47.2(12.8)$ & 134 & $50.0(11.2)$ & 147 & $48.8(11.8)$ & 37 & $51.2(10.9)$ \\
\hline Trea & Related Factors & & & & & & & & & & \\
\hline & Synovial Fluid Aspiration, frequency (\%) & 199 & $89(44.7)$ & 53 & $32(60.4)$ & 146 & $57(39.0)$ & 159 & $73(45.9)$ & 40 & $16(40.0)$ \\
\hline & Ultrasound-guided knee injection, frequency (\%) & 199 & $79(39.7)$ & 53 & $18(34.0)$ & 146 & $61(41.8)$ & 159 & $62(39.0)$ & 40 & $17(42.5)$ \\
\hline Cliniça $-R$ & ated Factors (subset $\mathrm{n}=101^{\dagger}$ ) & & & & & & & & & & \\
\hline Kneęar & $\begin{array}{l}\text { uadriceps Muscle Strength (Nm/kg), median (IQR) } \\
\text { of Movement (degrees), median (IQR) }\end{array}$ & 98 & $0.6(0.4$ to 1.1$)$ & 23 & $0.7(0.3$ to 1.5$)$ & 75 & $0.6(0.4$ to 1.1$)$ & 77 & $0.6(0.3$ to 1.0$)$ & 21 & $1.0(0.5$ to 1.2$)$ \\
\hline ס & Flexion & 101 & $120.0(111.0$ to 127.0$)$ & 23 & $122.0(106.0$ to 127.0$)$ & 78 & $120.0(112.0$ to 127.0$)$ & 79 & $120.0(111.0$ to 126.0$)$ & 22 & $121.0(114.0$ to 128.0$)$ \\
\hline 工 & Extension & 101 & $172.0(170.0$ to 176.0$)$ & 23 & $172.0(170.0$ to 177.0$)$ & 78 & $172.0(170.0$ to 176.0$)$ & 79 & $172.0(170.0$ to 176.0$)$ & 22 & $172.0(170.0$ to 177.0$)$ \\
\hline
\end{tabular}

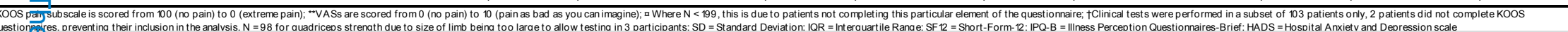


Tabe

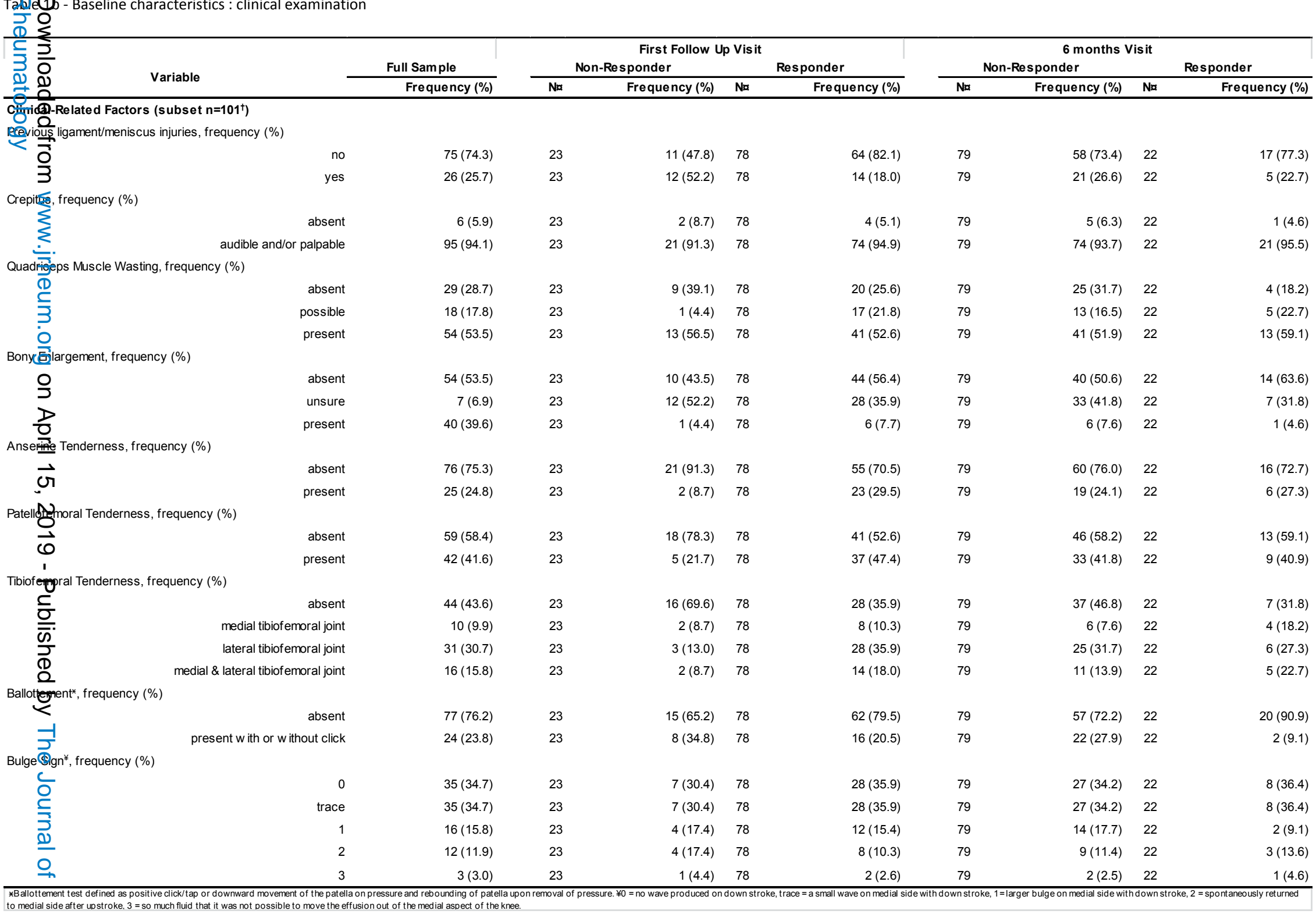


Table 2 - Baseline characteristics in those who had unguided and ultrasound-guided injections

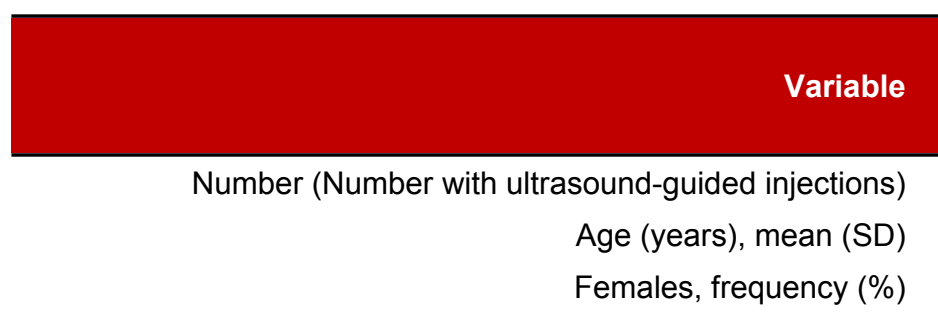

Number of days to follow up appointment, median (IQR)

KOOS pain subscale score $(0-100)^{\star}$, median (IQR)

Pain on nominated activity VAS $(0-10)^{* *}$, median (IQR)

Pain in last week VAS $(0-10)^{* *}$, median (IQR)
Participants with

unguided

injection

Participants with

ultrasound-guided

injection

120

79

$62.3(10.3)$

$63.5(10.4)$

$62(51.7)$

8.0 (7.0 to 14.0$)$

$43(54.4)$

$8.0(7.0$ to 14.0$)$

44.4 (36.1 to 55.6 )

41.7 (36.1 to 52.8 )

$7.0(5.5 \text { to } 7.7)^{\text {a }}$

$7.2(5.8 \text { to } 8.4)^{\dagger}$

$6.5(4.7 \text { to } 7.8)^{\text {a }}$

$6.6(5.3 \text { to } 8.3)^{\dagger}$

$61(77.2)$

No. of responders to injection, at follow-up visit, frequency (\%)

85 (70.8)

${ }^{*}$ KOOS pain subscale is scored from 100 (no pain) to 0 (extreme pain); ${ }^{* *} V A S s$ are scored from 0 (no pain) to 10 (pain as bad as you can imagine); ${ }^{5} 5$ and 3 participants neglected to complete their pain on nominated activity VAS and pain in last week VAS, respectively; 4 and 2 participants negin on nominated activity VAS and pain in last week VAS, respectively; SD = Standard Deviation; IQR = Interquartile Range
pain on

Downloaded from www.jrheum.org on April 15, 2019 - Published by The Journal of Rheumatology 
Table 3 - Short-term and longer-term prediction of response to IASI : Patient and treatment factors

\begin{tabular}{|c|c|c|c|c|}
\hline \multirow{2}{*}{ Predictor Variable in Regression } & \multicolumn{2}{|c|}{ Short-Term Responder (Yes/No) } & \multicolumn{2}{|c|}{ Longer-Term Responder (Yes/No) } \\
\hline & $\mathbf{N}$ & Relative Risk ( $95 \% \mathrm{Cl})$ & $\mathbf{N}$ & Relative Risk (95\% CI) \\
\hline \multicolumn{5}{|l|}{ Demographic / Prior Knee Injury } \\
\hline Age (per year) & 199 & $1.00(0.99$ to 1.01$)$ & 199 & $0.98(0.95$ to 1.01$)$ \\
\hline Gender (female vs male [ref.]) & 199 & $1.18(0.99$ to 1.40$)$ & 199 & 1.09 (0.63 to 1.91$)$ \\
\hline \multicolumn{5}{|l|}{ Symptoms } \\
\hline Pain on nominated activity VAS $(0-10 \mathrm{~cm})$ & 190 & 1.01 (0.96 to 1.06$)$ & 190 & 1.08 (0.91 to 1.27$)$ \\
\hline Pain in the last week VAS $(0-10 \mathrm{~cm})$ & 194 & $1.01(0.97$ to 1.05$)$ & 194 & $1.05(0.92$ to 1.21$)$ \\
\hline Number of Pain Sites (range 0-10) & 177 & 0.98 (0.94 to 1.02$)$ & 177 & $0.83(0.72$ to 0.97$)$ \\
\hline Chronic Widespread Pain (ACR) & 150 & 0.95 (0.76 to 1.19$)$ & 150 & $0.32(0.10$ to 0.98$)$ \\
\hline \multicolumn{5}{|l|}{ Psychological factors } \\
\hline HAD - Anxiety (0-21) & 170 & $0.99(0.97$ to 1.01$)$ & 170 & $0.93(0.86$ to 1.01$)$ \\
\hline HAD - Depression (0-21) & 170 & $0.98(0.95$ to 1.01$)$ & 170 & 0.89 (0.81 to 0.99$)$ \\
\hline IPQ-B Consequences Score (0-10) & 175 & $1.00(0.97$ to 1.04$)$ & 175 & $0.93(0.83$ to 1.05$)$ \\
\hline IPQ-B Timeline Score $(0-10)$ & 172 & 0.98 (0.95 to 1.02$)$ & 172 & $0.86(0.78$ to 0.94$)$ \\
\hline IPQ-B Personal Control Score $(0-10)$ & 173 & $1.00(0.97$ to 1.04$)$ & 173 & $0.99(0.89$ to 1.10$)$ \\
\hline IPQ-B Treatment Score $(0-10)$ & 174 & 1.05 (1.01 to 1.09$)$ & 174 & $1.08(0.94$ to 1.24$)$ \\
\hline IPQ-B Identity Score $(0-10)$ & 175 & 1.01 (0.97 to 1.06$)$ & 175 & $0.98(0.85$ to 1.13$)$ \\
\hline IPQ-B Illness Concern Score (0-10) & 174 & $1.00(0.97$ to 1.04$)$ & 174 & 0.95 (0.85 to 1.07$)$ \\
\hline IPQ-B Coherent Score $(0-10)$ & 172 & 1.03 (0.98 to 1.08$)$ & 172 & $1.12(0.95$ to 1.32$)$ \\
\hline IPQ-B Emotional Representation Score $(0-10)$ & 172 & 0.99 (0.96 to 1.02$)$ & 172 & 0.97 (0.88 to 1.07$)$ \\
\hline \multicolumn{5}{|l|}{ Quality of life } \\
\hline SF-12 Physical Component Summary $(0-100)$ & 184 & $1.00(0.99$ to 1.01$)$ & 184 & $1.00(0.97$ to 1.04$)$ \\
\hline SF-12 Mental Component Summary (0-100) & 184 & $1.00(1.00$ to 1.01$)$ & 184 & 1.01 (0.99 to 1.04$)$ \\
\hline \multicolumn{5}{|l|}{ Treatment-Related Factors } \\
\hline Synovial Fluid Aspiration (yes vs no [ref.]) & 199 & $0.79(0.66$ to 0.95$)$ & 199 & $0.82(0.47$ to 1.45$)$ \\
\hline Ultrasound-guided knee injection (vs unguided [ref.]) & 199 & 1.09 (0.92 to 1.29$)$ & 199 & $1.16(0.57$ to 2.34$)$ \\
\hline
\end{tabular}

[ref.] indicates the reference category in the log-binomial regression - e.g. yes vs no [ref]] indicates that ' $n$ ' was the reference category.

Downloaded from www.jrheum.org on April 15, 2019 - Published by The Journal of Rheumatology 
Table 4 - Short-term and longer-term prediction of response to IASI in subsample ${ }^{\dagger}$

\begin{tabular}{ccc}
\hline \multirow{2}{*}{ Predictor Variable in Regression } & $\begin{array}{c}\text { Short-Term Responder } \\
\text { (Yes/No) }\end{array}$ & $\begin{array}{c}\text { Longer-Term Responder } \\
\text { (Yes/No) }\end{array}$ \\
\cline { 2 - 3 } & Relative Risk $(95 \% \mathrm{Cl})$ & Relative Risk (95\% Cl) \\
\hline
\end{tabular}

Previous ligament/meniscus injuries, frequency (\%)

$\begin{array}{lll}\text { No } & \text { Reference category } & \text { Reference category } \\ \text { Yes } & 0.63(0.44 \text { to } 0.91) & 0.86(0.35 \text { to } 2.10)\end{array}$

Crepitus $^{a}$

Absent Reference category Reference category

Audible and/or palpable $\quad 1.17$ (0.66 to 2.08$) \quad 1.33(0.21$ to 8.26$)$

Quadriceps Muscle Wasting ${ }^{\text {" }}$

$\begin{array}{rrr}\text { Absent } & \text { Reference category } & \text { Reference category } \\ \text { Possible } & 1.37(1.05 \text { to } 1.79) & 2.01(0.62 \text { to } 6.53) \\ \text { Present } & 1.10(0.83 \text { to } 1.47) & 1.75(0.63 \text { to } 4.87)\end{array}$

Bony Enlargement ${ }^{\mathrm{a}}$

$\begin{array}{ccc}\text { Absent } & \text { Reference category } & \text { Reference category } \\ \text { Unsure } & 1.05(0.76 \text { to } 1.46) & 0.55(0.08 \text { to } 3.57) \\ \text { Present } & 0.86(0.68 \text { to } 1.09) & 0.68(0.30 \text { to } 1.52)\end{array}$

Anserine Tenderness

$\begin{array}{ccc}\text { Absent } & \text { Reference category } & \text { Reference category } \\ \text { Present } & 1.27(1.06 \text { to } 1.52) & 1.14(0.50 \text { to } 2.59)\end{array}$

Patellofemoral Tenderness

$\begin{array}{ccc}\text { Absent } & \text { Reference category } & \text { Reference category } \\ \text { Present } & 1.27(1.04 \text { to } 1.55) & 0.97(0.46 \text { to } 2.06)\end{array}$

Tibiofemoral Tenderness

$\begin{array}{rcc}\text { Absent } & \text { Reference category } & \text { Reference category } \\ \text { Lateral tibiofemoral Joint } & 1.26(0.86 \text { to } 1.84) & 2.51(0.91 \text { to } 6.96) \\ \text { Medial tibiofemoral Joint* } & 1.42(1.10 \text { to } 1.82) & 1.22(0.45 \text { to } 3.27) \\ \text { al \& lateral tibiofemoral joint } & 1.38(1.03 \text { to } 1.84) & 1.96(0.73 \text { to } 5.31)\end{array}$
Ballottement

$\begin{array}{rrr}\text { Absent } & \text { Reference category } & \text { Reference category } \\ \text { Present with or without click } & 0.83(0.61 \text { to } 1.12) & 0.32(0.08 \text { to } 1.27)\end{array}$

Bulge Sign ${ }^{a}$

\begin{tabular}{|c|c|c|}
\hline 0 & Reference category & Reference category \\
\hline Trace & $1.00(0.79$ to 1.26$)$ & $1.00(0.42$ to 2.36$)$ \\
\hline 1 & $0.94(0.68$ to 1.30$)$ & 0.55 (0.13 to 2.29$)$ \\
\hline 2 & $0.83(0.54$ to 1.28$)$ & 1.09 (0.35 to 3.47$)$ \\
\hline 3 & $0.83(0.37$ to 1.89$)$ & $1.46(0.26$ to 8.08$)$ \\
\hline Quadriceps Muscle Strength $(\mathrm{Nm} / \mathrm{kg})$ & $0.92(0.74$ to 1.16$)$ & $1.45(0.73$ to 2.85$)$ \\
\hline \multicolumn{3}{|l|}{ Knee Range of Movement (degrees) } \\
\hline Flexion $\left(0^{\circ}-180^{\circ}\right)$ & 1.00 (0.99 to 1.01$)$ & 1.01 (0.98 to 1.04$)$ \\
\hline
\end{tabular}


${ }^{t} \mathrm{~N}=101$ in all variables apart quadriceps muscle strength where $\mathrm{N}=98$ due to size of limb being too large to allow testing in 3 participants. ${ }^{\mathrm{D}}$ Further testing done using pairwise comparisons for equality by creating dummy variable coding confirms nonsignificance. ${ }^{*}$ Further testing done using pairwise comparisons for equality by creating dummy variable coding confirms medial tibiofemoral joint tenderness improved response at short-term only. Rheumatology 